\title{
Filter media expansion during backwash: The effect of biological activity
}

\author{
Michele Clements and Johannes Haarhoff* \\ RAU Water Research Group, Department of Civil and Urban Engineering, Rand Afrikaans University, PO Box 524, \\ Auckland Park 2006, South Africa
}

\begin{abstract}
Close observation at a number of South African water treatment plants has shown that media losses during backwashing are excessive - much higher than anticipated. The only likely reasons for this phenomenon are either that insufficient freeboard was provided by the designer or that the mechanical behaviour of the media gradually changes after being placed in the filters. A number of media tests confirmed that the biological fraction of the specific deposit on the filter media (after backwashing) is relatively high - about $50 \%$ of the total specific deposit. This led to the hypothesis that the combination of high nutrient concentrations in surface waters, coupled with elevated water temperatures, stimulate biofilm formation on the media grains. These films, in turn, somehow affect the mechanical behaviour of the media bed expansion and backwash. This paper reviews the Dharmarajah bed expansion model (as the most advanced model for media expansion to date) and presents evidence that it predicts the expansion of clean, ovendried media reasonably well. It further shows that media from filters which have been in operation for a while, expand significantly more than predicted by the Dharmarajah model. This finding has major implications for filter design, and suggestions are made on how to adapt design procedures for what is now believed to be the formation of biofilm on media grains.
\end{abstract}

\section{Introduction}

Designers of water filtration plants need to accurately predict the expansion of filter media when the filters will be backwashed. The expansion determines the minimum freeboard between the top of the media and the lip of the backwash overflow weir to prevent the large-scale washout of filter media during the backwash cycle. The best design practice at present is to either conduct experimental tests on the media selected for the plant or, more commonly, to use the grading analysis of an oven-dried sample in conjunction with a theoretical bed expansion model.

Over a number of years, observations at numerous treatment plants suggested that these approaches are possibly flawed. Media losses are almost consistently more than anticipated, as evidenced by a media surface level well below the originally specified media level. The trapping of underfloor air is a well known reason for media loss - when the air bubbles are inadvertently released during the "water only" backwash phase, a cloud of media is suspended in the water above the media and dropped over the overflow weir before it can settle again. But even where this problem was eliminated, a problem with excessive media loss was evident. This eventually led to a study to systematically investigate other possible reasons for what was observed.

This paper reports on the following parts of the investigation:

- A review of mathematical granular bed expansion models

- The results of a treatment plant survey where the expansion of filter media in actual use was measured, followed by identical tests after drying the same media sample in an oven

- A discussion of the implications for filter design

This paper was originally presented at the 2004 Water Institute of South Africa (WISA) Biennial Conference, Cape Town, South Africa, 2-6 May 2004.

* To whom all correspondence should be addressed.

酉+2711 489-2148; fax: +2711 489-2148 ; e-mail: jh@ing.rau.ac.za

\section{A review of mathematical bed expansion models}

The widely cited correlation by Richardson and Zaki (1954) applies to spherical particles and relies on the backwash velocity, the media porosity and some empirical relationships using the Reynolds number of the particles when settling:

$$
\begin{aligned}
& \frac{V_{a}}{V_{i}}=\varepsilon^{n} \\
& \text { for } 1<\mathrm{R}_{\mathrm{s}}<200 \mathrm{n}=(4.45+18 \mathrm{~d} / \mathrm{D}) \mathrm{R}_{\mathrm{s}}^{-0.1}
\end{aligned}
$$

Cleasby and Fan (1981) extended this approach to allow for nonspherical particles by adapting the ' $n$ ' in the Richardson-Zaki model by using the dynamic shape factor DSF as a measure of particle sphericity. The following expression was solved for the exponent ' $\alpha$ ', which would satisfy the expression for each media and size:

$$
\mathrm{n}_{\text {(actual) }}=\mathrm{n}_{\text {(spherical) }} \mathrm{DSF}^{\mathrm{a} \check{ }}
$$

The DSF is measured by

$$
D S F=\left(\frac{V_{s}}{V_{n}}\right)^{2}
$$

Other models by Sholji and Johnson (1987) and Quaye (1987) attempted to introduce a measure of the particle sphericity by using the particle settling velocity as one of the variables, but still required additional variables to obtain a reasonable fit. A recent model by Dabrowski et al. (2002) reverts to an empirical approach, which requires a newly calibrated equation for every new media sample.

The most comprehensive model to date is that of Dharmarajah and Cleasby (1986). Dharmarajah developed a correlation to predict the velocity-voidage relationship using Blake's modified Reynolds number $\left(\operatorname{Re}_{\mathrm{B}}\right)$ and a voidage function that is dependent on the Galileo number and the porosity of the bed. A fluidized system is considered to be fully defined by the following parameters: 
superficial velocity $V$, fluid density $\rho$, fluid viscosity $\mu$, particle density $\rho_{\mathrm{s}}$, particle specific surface area $s$, voidage of the bed $\varepsilon_{\mathrm{e}}$, acceleration resulting from gravity $g$ and a shape factor such as sphericity for non-spherical particle systems $\psi$. Because there are eight parameters (including $\psi$ ) and three primary dimensions, five dimensionless groups can be written:

$$
\left(g / s V^{2}\right),(\rho V / s \mu),\left(\rho_{s}-\rho\right) / \rho, \varepsilon_{e}, \psi
$$

Dharmarajah manipulated these groups to eventually get the following correlations:

$$
\operatorname{Re}_{B}=\frac{V}{\varepsilon_{e}}\left[\frac{\varepsilon_{e}}{\left(1-\varepsilon_{e}\right) s}\right]\left(\frac{\rho}{\mu}\right)=\frac{\rho V}{s \mu\left(1-\varepsilon_{e}\right)}
$$

Followed by:

$$
\Phi=\frac{g\left(\rho_{s}-\rho\right) \varepsilon_{e}{ }^{3}}{s \rho V^{2}}
$$

Because both $\Phi$ and $\operatorname{Re}_{\mathrm{B}}$ contain $V$, Dharmarajah defined a new function $A 1$ that is not a function of $V$. A1 was defined as:

$$
\begin{aligned}
& A 1=\Phi \times \operatorname{Re}_{\mathrm{B}}^{2} \\
& \log \frac{\varepsilon_{e}^{3}}{\left(1-\varepsilon_{e}\right)^{2}} \frac{\rho\left(\rho_{s}-\rho\right) g}{s^{3} \mu^{2}}= \\
& =\mathrm{a}_{0}+\mathrm{a}_{1} \log \operatorname{Re}_{\mathrm{B}}+\mathrm{a}_{2}\left(\log \operatorname{Re}_{\mathrm{B}}\right)^{2} \\
& +\mathrm{a}_{3}\left(\log \operatorname{Re}_{\mathrm{B}}\right)^{3}+\mathrm{a}_{4}\left(\log \operatorname{Re}_{\mathrm{B}}\right)^{4}
\end{aligned}
$$

For non-spherical particles

$$
s=6 /\left(\psi d_{e q}\right)
$$

Because coefficient $a_{3}$ was found to be not significantly different from zero, it was eliminated from the equation. An additional term involving $\log \psi$ was included to fine-tune the data point represented by the non-spherical particles. After calibrating with his own and with published data, Dharmarajah found that the general equation to describe the expansion behavior of spherical as well as non-spherical particles when $R e_{B}>0.2$ is

$$
\begin{aligned}
& \log \mathrm{A} 1=0.56543+1.09348 \log \operatorname{Re}_{\mathrm{B}}+0.17979\left(\log \operatorname{Re}_{\mathrm{B}}\right)^{2} \\
& -0.00392\left(\log \mathrm{Re}_{\mathrm{B}}\right)^{4}-1.5(\log \psi)^{2}
\end{aligned}
$$

The model is structured in terms of $\varepsilon$, which is related to linear bed expansion by:

$$
\mathrm{l}_{\mathrm{e}} / \mathrm{l}=1-\varepsilon / 1-\varepsilon_{\mathrm{e}}
$$

There are three critical parameters in the Dharmarajah model, which warrant further discussion, namely the particle diameter, the porosity of the bed before expansion and the sphericity of the particles. The other parameters are readily available from the literature (water density and viscosity), easily measured (media density) or part of the design parameters (bed depth before expansion, backwash velocity).

The particle diameter can practically be determined by two methods. The most common is by sieve analysis, which returns a size distribution in terms of the size of the apertures of the sieves used. This method is often criticised on the basis that it is ultimately the smallest dimension that is measured in this way, rather than the average diameter. The alternative method is the more tedious count-and-weigh method, where 100 grains of each size fraction are manually counted and weighed after the sieve analysis. By knowing the particle density, the average volume and thus the diameter of an equivalent sphere can be calculated. Both methods were used in the study reported here with very little difference between them. In the interest of brevity, only the diameters obtained by the count-and-weigh method are reported in this paper. Bed porosity is not a constant characteristic of a granular bed. A bed, which is hydraulically or physically jolted, will collapse or compact slightly resulting in lower bed porosity. This is especially evident when conducting tests in the laboratory, where a wide range of values for the bed porosity can be obtained on the same sample, depending on how the test is conducted. For the comparisons between different media samples, doubtful measured values were abandoned and a constant porosity of 0,50 was used.

The sphericity of the media is the most elusive parameter to account for. There are many measures of sphericity, but the surface area sphericity of a grain is most commonly used, which is defined as the ratio of the surface area of an equivalent-volume sphere to the actual grain surface area. Practically all methods, however, do not attempt to measure sphericity directly but rather leave it as the only unknown in equations for bed expansion or head loss, to be solved mathematically. In this way, it is not really known whether if it solely accounts for sphericity, or also inadvertently also accounts for other effects. In other words, it may also be an overall calibration factor without physical meaning. In another part of this study not reported here, it was shown that this is indeed the case. By simultaneous application of the Ergun head loss and Dharmarajah bed expansion equations (both using the surface area sphericity as input variable) it was found the same surface area sphericity could not satisfy both equations simultaneously. Although one obviously accepts that the surface area sphericity plays a large role in bed expansion, we accept for the purpose of this paper that the term for sphericity can also be used as a calibration factor.

\section{A practical bed expansion model}

The Dharmarajah model is computationally complex and it is not easy to appreciate the effect of individual variables on bed expansion. Moreover, its structure is such that it not easy to find a leastsquare solution to experimental data. As an alternative, a simple exponential model was postulated which accounts for all the variables contained in the Dharmarajah model:

$$
\mathrm{l}_{\mathrm{e}} / \mathrm{l}=\mathrm{K} \cdot \varphi^{\mathrm{a}} \cdot \varepsilon^{\mathrm{b}} \cdot\left(\rho_{\mathrm{s}}-\rho\right)^{\mathrm{c}} \cdot \mu^{\mathrm{d}} \cdot \mathrm{V}^{\mathrm{e}} \cdot \mathrm{d}_{\mathrm{eq}}{ }^{\mathrm{f}}
$$

This equation was calibrated against the Dharmarajah model with a least-square model. For each of the six variables, five numerical values were chosen to cover a practical range of values, resulting in $6^{5}$ combinations of input variables. For each, the bed expansion was calculated with the Dharmarajah model. The 15625 bed expansion values were subsequently screened to retain only those 3886 values between expansion of $10 \%$ and $60 \%$ - the practical range of bed expansion in practice. Using these values yielded the calibrated version of Eq. 11:

$$
l_{e} / l=3.284 \varphi^{-0.358} \varepsilon^{-0.868}\left(\rho_{s}-\rho\right)^{-0.341} \mu^{0.235} V^{0.414} d_{e q}{ }^{-0.583}[12]
$$

The maximum deviation between the results obtained by the original and the simplified Dharmarajah model was found to be $9.5 \%$, the minimum deviation $-9.9 \%$ and the average deviation $0.2 \%$.

A real media bed contains a range of grain diameters. To account for this, the bed has to be discretised over a number of assumed homogeneous layers and the bed expansion model applied to each, before being added together. For m layers, the equation is adapted: 
$l_{e} / l=3.284 \varphi^{-0.358} \varepsilon^{-0.868} \mu^{0.235} V^{0.414} \sum_{m}\left(\rho_{s}-\rho\right)^{-0.341} d_{e q}{ }^{-0.583}$

Equation 13 will allow the analysis of a bed composed of grains with different densities. If the bed is composed of grains with homogenous density, the density term can be brought forward to before the summation sign. If the actual bed expansion is measured at a single flow rate, the sphericity can be directly calculated from the above equation. If the bed expansion is measured at $n$ different flow rates, the sphericity is best determined with a least-square approach (the exponents are left in symbolic form):

$$
\begin{aligned}
& S S=\sum_{n} l_{e}^{* 2}-2 \sum_{n} l_{e}^{*} l_{e}+\sum_{n} l_{e}^{2} \\
& S S=l_{e}^{2}-2 \sum_{n} l_{e}^{*}\left[K \phi^{a} E^{b} \mu^{d} V^{e} \sum_{m} l_{m}\left(\rho_{s}-\rho\right)^{c} d^{f}\right] \\
& +\sum_{n}\left[K \phi^{a} E^{b} \mu^{d} V^{e} \sum_{m} l_{m}\left(\rho_{s}-\rho\right)^{c} d^{f}\right]^{2} \\
& \frac{\partial S S}{\partial \phi}=-2 K E^{b} \mu^{d} \sum_{m} l_{m}\left(\rho_{s}-\rho\right)^{c} d^{f} \sum_{n}\left(l_{e}^{*} V^{e}\right) a \phi^{a-1} \\
& +K^{2} E^{2 b} \mu^{2 d}\left[\sum_{m} l_{m}\left(\rho_{s}-\rho\right) d^{f}\right]^{2} \sum_{n} V^{2 e} 2 a \phi^{2 a-1}=0
\end{aligned}
$$

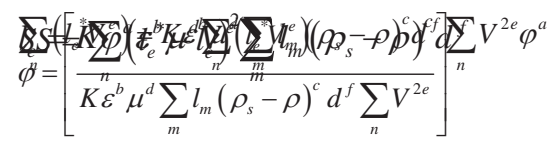

Now substituting K, a, b, c, d, e, f:

$$
\varphi=\left[\frac{\sum_{n}\left(l_{e}^{*} V^{0.414}\right)}{3.284 \varepsilon^{-0.868} \mu^{0.235} \sum_{m} l_{m}\left(\rho_{s}-\rho\right)^{-0.341} d_{e q}{ }^{-0.583} \sum_{n} V^{0.828}}\right]^{\frac{1}{-0.358}}
$$

\section{Experimental and computational procedures}

Several plants were investigated and a sample of $\pm 2 \mathrm{~kg}$ filter media was obtained after backwashing at each plant. Bed expansion was subsequently measured in a portable column, $100 \mathrm{~mm}$ in diameter and $1000 \mathrm{~mm}$ in length; by increasing the upward flow $\mathrm{V}$ through the column and then noting the subsequent expansion of the media. The temperature of the water flowing through the column was also noted. The sample was then transported back to the laboratory and placed in an oven for $24 \mathrm{~h}$ at $110^{\circ} \mathrm{C}$. The sample was sieved during a particle sieve analysis to calculate $\mathrm{d}_{\mathrm{g}}$ and each sieve fraction was tested for density with a picnometer and the $\mathrm{d}_{\mathrm{eq}}$ determined by means of the count and weigh method. The bed expansion was then once again measured in the same portable column, on the same sample that had now been dried and sieved.

Using Eq. 21, the sphericity for a chosen porosity (as discussed previously) is calculated using $l_{e}^{*}$ which is the measured data obtained the during the bed expansion test on the sample retrieved at the plant. This sphericity is thus calibrated with the measured data. The sum of the measured velocities is used and the dynamic viscosity and water density incorporates the temperature of the water. The $\mathrm{d}_{\mathrm{eq}}$ and media density of every fraction of the sieve analysis are obtained as discussed above, and all values are summated as per Eq. 21. This calculated sphericity is then used to calculate bed expansion as per Eq. 12, for each of the given velocities at which real measurements were taken. The procedure was repeated for measured data obtained during the bed expansion test on the same sample after it had been dried and sieved. The original Dharmarajah equation was also modelled and compared to the results of the simplified Dharmarajah equation.

\section{Results}

Using the results obtained by Eq. 13, for several velocities and for a chosen porosity of 0.5 , the following comparison in Fig. 1 is achieved.

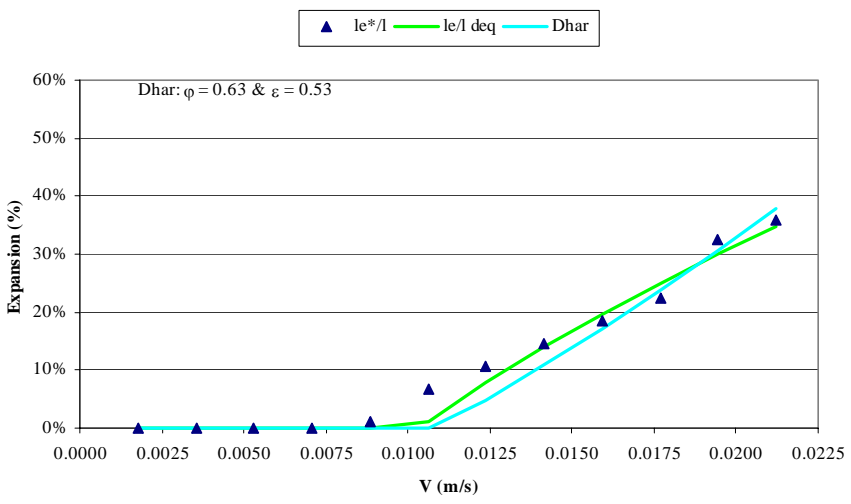

Figure 1

Measured vs calculated bed expansion for Rietvlei after drying and sieving, where $I_{\mathrm{e}}^{*} / l$ is the measured bed expansion, $I_{\mathrm{e}} / l d_{\mathrm{eq}}$ is the predicted bed expansion as calculated by the new model and Dhar is results of the original Dharmarajah equation

When one compares the data before and after drying and sieving, once again we find a great difference, ascribed to biofilm:

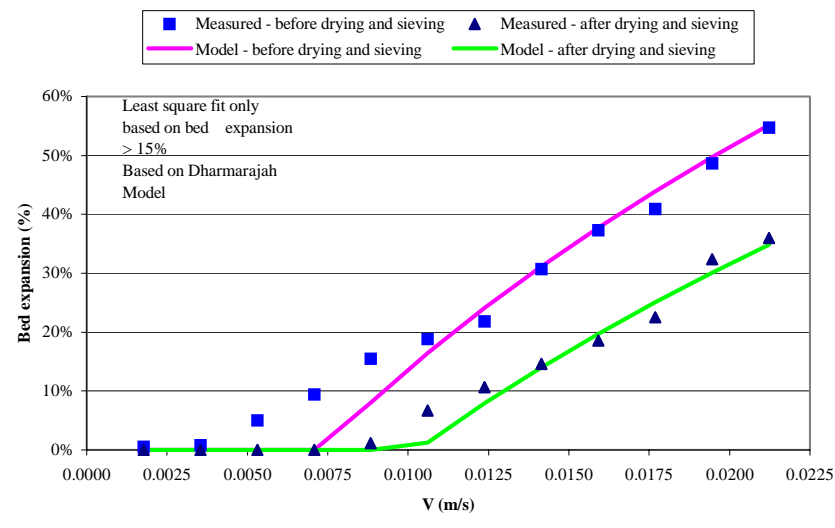

Figure 2

Measured vs calculated bed expansion: before and after drying and sieving - Rietvlei

One can see that the original Dharmarajah equation predicts the expansion of clean, oven-dried media reasonably well, but that the media that had been in operation, expanded significantly more than predicted by that the original Dharmarajah model. Between 0 $15 \%$ expansion, the whole bed expands more than it theoretically 
should. This might be ascribed to the upward force of the water pushing the bed up as a whole whereafter this 'solid' bed breaks apart.

Similar test were performed at three other treatment plants and the results are shown in Figs 3 to 5:

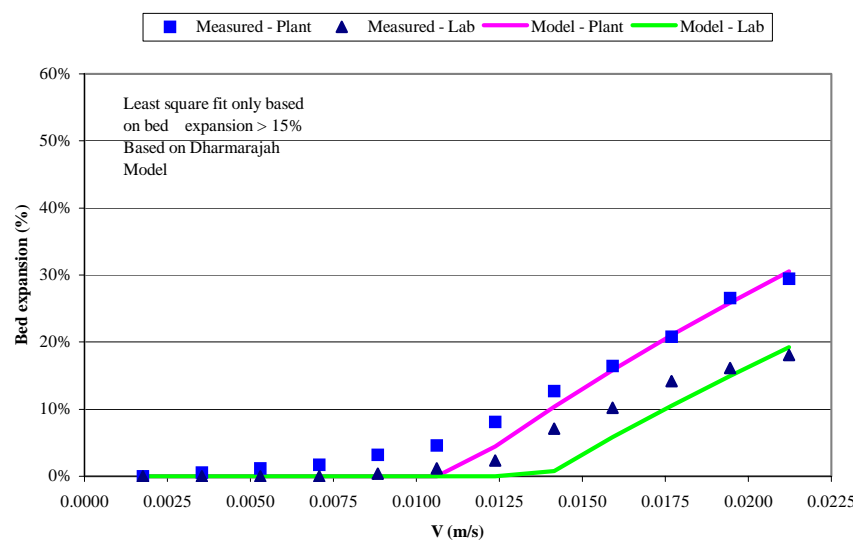

Figure 3

Measured vs. calculated bed expansion: before and after drying and sieving - Vaalkop

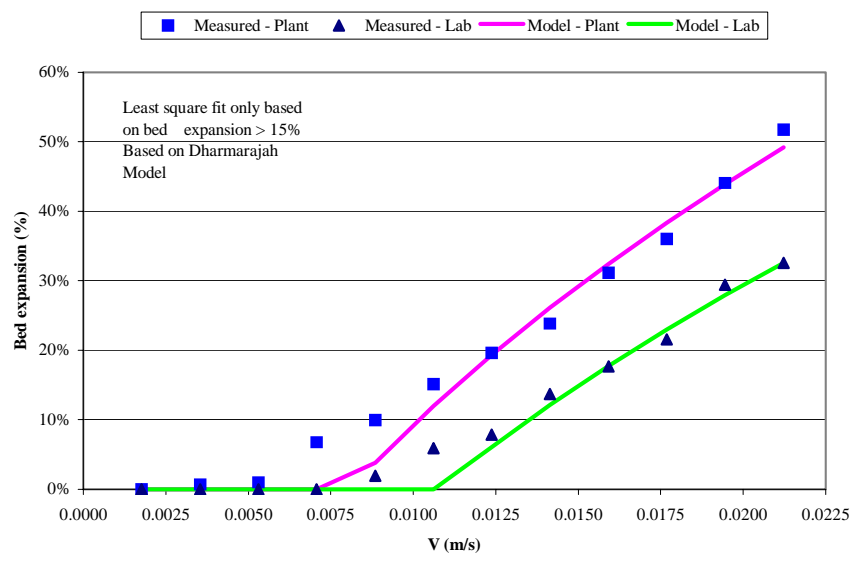

Figure 4

Measured vs calculated bed expansion: before and after drying and sieving - Midvaal

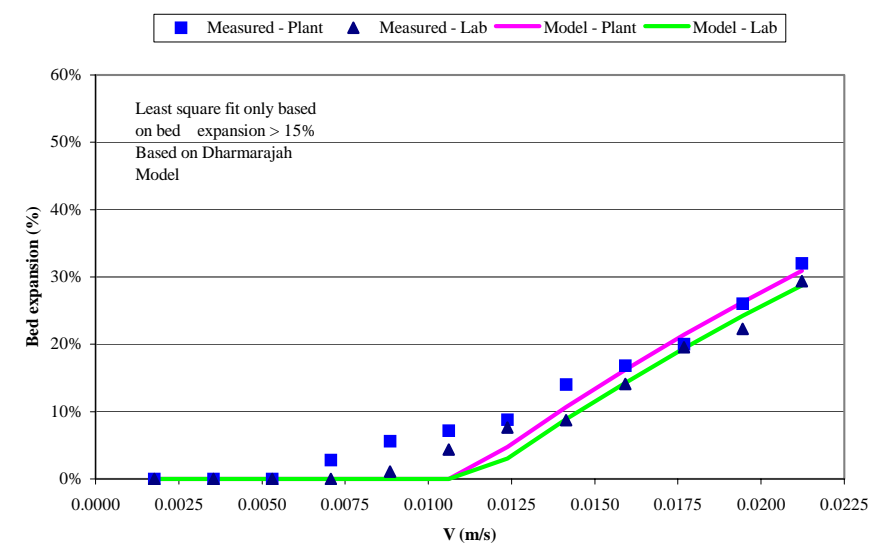

Figure 5

Measured vs calculated bed expansion: before and after drying and sieving - Rand Water 3
The decrease in the percentage expansion on the same sample after drying and sieving is a consistent phenomenon. However, the plant represented by Fig. 5, is a relatively new plant with little decrease in the percentage expansion after drying and sieving, confirming the hypothesis that this increase in percentage bed expansion happens over a space of time, with the growth of biological activity.

\section{Discussion}

Using Eq. 21 at a given porosity, there is a correlating sphericity, which changes after being dried and sieved for that same porosity. If all the visited plant are considered at a porosity of 0.5 , the following changes in calculated sphericity occurs:

\begin{tabular}{|c|c|c|c|c|}
\hline \multicolumn{5}{|c|}{$\begin{array}{c}\text { TABLE } 1 \\
\begin{array}{c}\text { Sphericity values calculated by bed expansion for all } \\
\text { plants }\end{array}\end{array}$} \\
\hline & \multicolumn{4}{|c|}{ Sphericity } \\
\hline & $\begin{array}{l}\text { Laboratory } \\
\quad(-)\end{array}$ & $\begin{array}{l}\text { Plant } \\
(-)\end{array}$ & $\begin{array}{c}\text { Difference) } \\
(\%\end{array}$ & $\begin{array}{l}\text { Volatile } \\
\text { fraction } \\
\quad(\%)\end{array}$ \\
\hline Rietvlei & 0.855 & 0.587 & $31.3 \%$ & $58 \%$ \\
\hline Vaalkop & 0.455 & 0.388 & $14.7 \%$ & $60 \%$ \\
\hline Stilfontein & 0.836 & 0.632 & $24.3 \%$ & $43 \%$ \\
\hline Rand Water 3 & 0.643 & 0.646 & $0.3 \%$ & $37 \%$ \\
\hline \multicolumn{5}{|c|}{$\begin{array}{l}{ }^{1} \text { Volatile (biological) fraction of deposits on media after } \\
\text { backwash (Van Staden and Haarhoff (2004) }\end{array}$} \\
\hline
\end{tabular}

When one considers the term for sphericity as a calibration factor, it is apparent that there is an increase in sphericity after the same sample is dried and sieved. Equation 12 shows it is clear that this 'lower' sphericity before drying and sieving will directly result in a higher initial expansion, accentuating the effect of this individual variable on bed expansion. Although there is not enough data at this point to prove it, it seems as if the change in sphericity is correlated to the period of time each plant has been in commission and the organic concentration in the raw water at each plant, as indicated in the last column of Table 1.

\section{Possible improvements to design procedures}

This paper presents compelling evidence that design procedures based on oven-dried laboratory samples will underestimate the expansion of the bed after it has been in service for a number of months or years. It seems appropriate to retain the Dharmarajah model as the basis of calculation, as it successfully accounts for all the physical parameters that affect bed expansion. One could then either apply a correction factor after application of the model to allow for more expansion during eventual plant operation, or one could adjust one of the existing parameters within the model to account for the larger expansion. As the surface area sphericity is practically anyway used as a calibration factor, it is suggested that this factor is used for adjustment of the model.

A logical next step then would be to determine by how much the surface area sphericity should be adjusted. Based on the limited data available and presented here, it seems that at worst the adjustment would have to be $-30 \%$ and at best no adjustment at all 
(all based on measurements made in winter with low water temperatures. This work is being continued to add more data points, covering all seasons. It appears as if the adjustment needs to be highest when eutrophic water with high nutrient content is treated, while turbid water with low nutrient content will not require adjustment at all, but this preliminary finding also has to be better supported by a more complete data base.

Until this issue is satisfactorily resolved, it is suggested that the surface area sphericity is determined through calibration of the Dharmarajah model, and that it is then adjusted downward by between $0 \%$ and $30 \%$ (depending on how eutrophic the raw water is) for the prediction of the media under actual plant operating conditions.

\section{List of symbols}

$\begin{array}{ll}a & =\text { constant } \\ A 1 & =\Phi \times \operatorname{Re}_{B}{ }^{2} \\ d / D & =\text { ratio of the particle diameter to column diameter } \\ d_{e q} & =\text { equivalent diameter of media grains } \\ D S F & =\text { dynamic shape factor } \\ g & =\text { gravitational acceleration } \\ l_{e} / l & =\text { bed expansion } \\ n & =\text { slope of log } \mathrm{V} \text { versus log } \varepsilon \text { plot } \\ R_{B} & =\text { Blake's modified Reynolds number } \\ R_{s} & =\left(\mathrm{d}_{\text {eq }} \mathrm{V} \rho\right) / \mu \text { (the particle Reynolds number) } \\ S & =\text { particle specific surface area } \\ V & =\text { empty bed velocity } \\ V_{a} & =\text { superficial velocity of the fluid above the bed } \\ V_{i} & =\text { intercept velocity at a porosity ratio of one }\end{array}$

$V_{m f}=$ minimum fluidisation velocity

$V_{n} \quad=\quad$ unhindered terminal settling velocity of equivalent volume spherical grains

$V_{\mathrm{s}} \quad=\quad$ unhindered terminal settling velocity of the grains

$\Phi=g\left(\rho_{s}-\rho\right) \varepsilon^{3} / s \rho V^{2}$

$\varepsilon \quad=$ fixed bed porosity

$\varepsilon_{\mathrm{e}} \quad=$ expanded bed porosity

$\varphi=$ sphericity of media grains

$\mu \quad=$ dynamic viscosity of water

$\rho=$ density of water

$\rho_{\mathrm{s}} \quad=$ density of media

\section{References}

CLEASBY JL and FAN KS (1981) Predicting fluidization and expansion of filter media. J. Sanit. Eng. Div. ACSE. 107.

DHARMARAJAH AH and CLEASBY JL (1986) Predicting the expansion behaviour of filter media. J. AWWA 78 (12) 66-76.

DBROWSKI W, SPACZYDSKA M and MACKIE RI (2002) A model to predict granular activated carbon expansion. Retrieved August 2, 2003 from the Internet: kfki.baw.de/conferences/ICHE/2002-Warsaw/ARTICLES/PDF/282F.pdf

QUAYE BA (1987) Predicting optimum backwash rates and expansion of multi-media filters. Water Res. 21 (9) 1077-1087.

RICHARDSON JF and ZAKI WN (1954) Sedimentation and fluidization, Part 1. Inst. of Chem. Eng. Trans. 32, London, England. 35-53.

SHOLJI I and JOHNSON FA (1987) Comparison of backwash models for granular media. J. of Environ. Eng. 113 (3) 516-531.

VAN STADEN SJ and HAARHOFF J (2004) What simple media test can tell you about filter problems and rehabilitation. 9th Bienn. Conf. of the Water Inst. of Southern Africa, held in Cape Town, 2-6 May. 